\title{
A new species of Charinus Simon, 1892 (Arachnida: Amblypygi: Charinidae) from Israel and new records of $C$. ioanniticus (Kritscher, 1959)
}

\author{
Gustavo S. MIRANDA ${ }^{1 *}$, Shlomi AHARON ${ }^{2}$, Efrat GAVISH-REGEV ${ }^{3}$, \\ Alessandro P.L. GIUPPONI ${ }^{4}$ \& Gil WIZEN ${ }^{5,6}$ \\ ${ }^{1}$ Center for Macroecology, Evolution and Climate, Natural History Museum of Denmark \\ (Zoological Museum), University of Copenhagen, Copenhagen, Denmark. \\ ${ }^{2}$ Blaustein Institutes for Desert Research, Ben-Gurion University of the Negev, \\ Sede Boqer Campus, Midreshet Ben-Gurion, 849900, Israel. \\ ${ }^{3}$ The National Natural History Collections, The Hebrew University of Jerusalem, \\ Edmond J. Safra Campus, Jerusalem, 9190401, Israel. \\ ${ }^{4}$ Laboratório de Referência Nacional em Vetores das Riquetsioses, \\ LIRN-FIOCRUZ, Rio de Janeiro, RJ, Brazil. \\ ${ }^{5}$ Faculty of Forestry, University of Toronto, Toronto, Ontario M5S 3B3, Canada. \\ ${ }^{6}$ Department of Zoology, Tel Aviv University, Tel Aviv, 6997801, Israel. \\ "Corresponding author: smiranda.gustavo@gmail.com \\ ${ }^{2}$ Email: shlomi.aharon@gmail.com \\ ${ }^{3}$ Email: efrat.gavish-regev@mail.huji.ac.il \\ ${ }^{4}$ Email: agiupponi@gmail.com \\ ${ }^{5}$ Email: wizentrop@gmail.com \\ ${ }^{1}$ urn:lsid:zoobank.org:author:AF7CC5D6-31CE-40D2-AC1E-9D24245D19C4 \\ ${ }^{2}$ urn:Isid:zoobank.org:author:FB5EEA73-DD16-440C-B611-07F1C0C1300B \\ ${ }^{3}$ urn:Isid:zoobank.org:author:FC073F19-2202-4C89-8B43-CEA4CC5E2D50 \\ ${ }^{4}$ urn:lsid:zoobank.org:author:434112AC-B212-43E8-A5D9-2F5D5619AFC4 \\ ${ }^{5}$ urn:lsid:zoobank.org:author:08A8140A-AF25-4275-9A01-32BADF0DFB04
}

\begin{abstract}
A new species of Charinus is described from Israel and new localities for C. ioanniticus are reported. Charinus israelensis sp. nov. is a cave dwelling species with extremely small median eyes, no median tubercle and reduced lateral eyes. It is similar to $C$. ioanniticus, which occurs in nearby areas, but can be differentiated by the shape of the carapace, the number of pedipalp spines and the development of the eyes. A detailed comparison is made between the two species, including pictures, drawings and scanning electron micrographs. Charinus ioanniticus is reported here from several new localities in Israel and Turkey. Identification keys to the Charinus species groups and to the species of the bengalensis group are provided.
\end{abstract}

Keywords. Biodiversity, caves, Palearctic, taxonomy, whip spider.

Miranda G.S., Aharon S., Gavish-Regev E., Giupponi A.P.L. \& Wizen G. 2016. A new species of Charinus Simon, 1892 (Arachnida: Amblypygi: Charinidae) from Israel and new records of C. ioanniticus (Kritscher, 1959). European Journal of Taxonomy 234: 1-17. http://dx.doi.org/10.5852/ejt.2016.234 


\section{Introduction}

Whip spiders are distributed in the tropical and sub-tropical regions of the world. Among the five families, Charinidae Quintero, 1986 is the most diverse in the order, with 88 species, and the genus Charinus Simon, 1892 is the largest of the family, with 70 described species. The majority of the known species is found in the Neotropics (Giupponi \& Miranda 2016; Miranda et al. 2016), and only three charinids are known from the Indomalayan and Palearctic regions: Charinus bengalensis (Gravely, 1911), C. ioanniticus (Kritscher, 1959) and C. pakistanus Weygoldt, 2005. These species belong to the bengalensis species group, which is characterized by the finger-like female gonopod. Two additional species groups are recognized in this genus: the brasilianus and australianus groups, which have sucker-like and cushion-like gonopods, respectively, and are found in the Americas, Africa and Oceania (Weygoldt 2005).

Despite being a Pleistocene refugium for several taxa and having a high degree of endemism (Husemann et al. 2014), the eastern Mediterranean counts thus far only one known species of Charinus, the parthenogenetic C. ioanniticus. This species is recorded from Greece (Kritscher 1959), Turkey (Kovařík \& Vlasta 1996; Weygoldt 2005; Seyyar \& Demir 2007), Egypt (El-Hennawy 2002) and Israel (Kraus 1961; Rosin \& Shulov 1960). It is the most widespread species of the genus, probably as a consequence of human activities, such as accidental transport with plants (Weygoldt 2005).

Whip spiders were found in a cave fauna survey in Israel (see Gavish-Regev et al. (2016) for details on the cave survey), as well as from occasional collecting events in caves. Among the specimens collected, several were noticeably different to the widespread species $C$. ioanniticus. We examined all whip spider material found in Israel and present here new data on the distribution of $C$. ioanniticus in Israel and Turkey. We also describe a new species, Charinus israelensis sp. nov. from a few different caves in the northern region of Israel, and provide keys to the Charinus species groups and to the species of the bengalensis group.

\section{Materials and methods}

\section{Permits and repository collection}

The specimens were collected with permits issued by the Nature and Parks Authority in Israel (permit numbers 2012/38653, 2013/40027, 2014/40313 and 2014/40503). The animals were found through visual searching along the walls and ceiling in the caves using a powerful LED headlamp. Specimens were captured by hand and placed in vials containing $70 \%$ ethanol, and were later deposited in the Israel National Arachnid Collection of The Hebrew University of Jerusalem and the National Museum of Rio de Janeiro. Some of the specimens were kept alive and taken to the laboratory for natural history and behavioral observations. Live specimens were kept in $10 \times 5 \times 5 \mathrm{~cm}$ acrylic containers (AMAC Plastics Ltd., California, USA) with moist peat substrate and a Styrofoam board placed diagonally as a resting spot. They were kept at $24^{\circ}-26^{\circ} \mathrm{C}$ in a dark room and were fed with live silverfish and cricket nymphs.

\section{Laboratory procedures}

The studied specimens were examined using a Leica M205C stereo microscope, which is attached to a camera lucida used for the drawings. Photographs were taken with a BK+ Imaging System from Visionary Digital (http://www.visionarydigital.com) equipped with a Canon EOS 7D camera at the Zoological Museum, Copenhagen (Denmark). Single images were combined with Helicon Focus (version 5.3; www.heliconsoft.com) software from Helicon Soft Ltd. to increase depth of field, and further processed in Photoshop CC to adjust color, brightness and contrast, and remove blemishes. SEM images were made with a JEOL JSM-6390 LV at Plataforma de Microscopia Eletrônica Rudolf Barth, FIOCRUZ-IOC, Rio de Janeiro (Brazil). 
Measurements and nomenclature follow Quintero (1981) in general. The pedipalp article, called tarsus by Quintero, is here divided into distitarsus and tarsal claw (pretarsus), as the two articles are not fused in Charinidae. The measurements of pedipalp articles were taken between the external condiles of each segment in order to establish fixed points and proper length measurements (Baptista \& Giupponi 2002). The sensilla names on the first leg follows Igelmund (1987). The measurements were taken from several specimens (number indicated as " $n=$ ") with the median value given first, followed by the range in parentheses. The measurement accuracy is indicated in the legend of each figure.

The following abbreviations are used for museums and other collections:

$\mathrm{AMNH}=$ American Museum of Natural History, New York

HUJINVAMB $=$ National Arachnid Collection, The Hebrew University of Jerusalem, Jerusalem

MZUF = Natural History Museum, Zoological Section 'La Specola' of the University of Florence, Florence

MHNG = Muséum d'Histoire naturelle de Genève, Geneva

MNRJ = National Museum, Rio de Janeiro

NHMW $\quad=$ Naturhistorisches Museum Wien, Vienna

SMF $\quad=$ Senckenberg Museum, Frankfurt

ZMUC = Zoological Museum, Natural History Museum of Denmark, Copenhagen

\section{Additional material analyzed}

Charinus abbatei Delle Cave, 1986: holotype, Somalia, Grotta do Showli Berdi, Bardera, Tratto 20, Campione 12, S.B.S.I., 15 Mar. 1984, Coll. 167 (1 $\&$, MZUF 1896).

Charinus africanus Hansen, 1921: syntypes, São Tomé e Príncipe, Annobon, 400-500 m, May 1902, L. Tea leg. (3 우, ZMUC00024552); syntypes, São Tomé e Príncipe, St. Thome, Vista Alegre, 200300 m, Sep.-Oct. 1900, L. Tea leg. (2 specimens, ZMUC00024545). Non types: São Tomé, near Sao

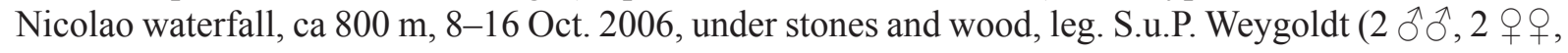
1 juvenile, $\mathrm{AMNH})$.

Charinus bengalensis (Gravely, 1911): holotype, India, West Bengal, Kolkata (as Calcutta), Indian Museum (1 0 , SMF 64590).

Charinus eleonorae Baptista \& Giupponi, 2003: holotype, Brazil, Minas Gerais, Itacarambi, Gruta Olhos d'Água, 26 Jun. 2001, R.L.C. Baptista and A.P.L. Giupponi leg. (1 đ̄, MNRJ 9070); paratypes, Brazil, Minas Gerais: Itacarambi, Gruta Olhos d'Água, 26 Jun. 2001, R.L.C. Baptista and A.P.L. Giupponi leg.

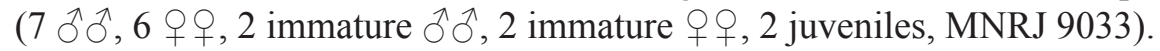

Charinus ioanniticus (Kritscher, 1959): syntypes, Greece: Island of Rhodos, Lindos, below castle, Paget, 3 Jul. 1969, Bilek leg. (1 + , NHMW 19138); Island of Rhodos, Lindos, Paget, 1963, Bilek leg. (5 우, NHMW 19137); same data (2 juveniles, NHMW 1427). Non-types, Greece: Rhodos, O. Bechtold leg. (2 우, 3 juveniles, MHNG); Dodekanes, Rhodos, Rhodos City, Jun. 1978, N. Polemikos leg. (1 +, SMF 56704); Rhodos, Lindos, castle of Johannites [= Monolithos], in wall and rock fissures of the substructure, 27 Apr. 1964, V. Helversen and H. Pieper leg. (6 웅, SMF 17319; 4 우오 SMF 17392); Kos, bunker of the castle, 30 Apr. 1965, H. Piepper leg., O. Kraus det. (6 우, SMF 17391); Rhodos, town of Lindos, Krichter leg. (1 +, SMF11895/1); Turkey: Iskenderun, Çevlik (Jeskyne), 36 $07^{\prime}$ N,

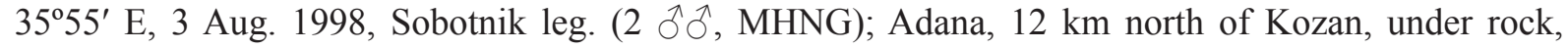
300 m, 5 May 1967, Cl. Besuchet leg., O. Kraus det. (1 §, MHNG); Yalan Dünya Cave, Beyrebucak Village, Gazipaşa District, Antalya Province, Turkey, 36²13'16.92" N, 32²4'4.43" E, 5 Dec. 2013, K.B. Kunt and Y.M.Marusik leg. (1 $q$, ZMUC00042413). Israel: Carmel Ridge, Haifa, 32 $47^{\prime} 47.50^{\prime \prime}$ N, 350'59.47" E, 24 Jun. 2014, G. Wizen leg. (1 ㅇ, HUJINVAMB 100); Haruba cave, 9 Mar. 2014, 
Aharon and Gavish-Regev leg. (1 9 , HUJINVAMB 119); Khirbet Roma, near Rumana, Beit Netofa Lower Galilee, 3247'20.39" N, 35¹7'35.18" E, 178 m, 21 Mar. 2015, Ori Segev leg. (HUJINVAMB 120); Jerusalem, Rosin leg., 4 May 1960 (1 q, SMF 12126/1; 1 q, SMF 12127/1).

Charinus pakistanus Weygoldt, 2005: holotype, Pakistan, Hazara, Malkandi, 1500 m, between Kawai and Mahandri, sieving of dead leaves and old tree stumps in a deciduous forest, 3 Jun. 1983, Cl. Besuchet and I. Löbl leg. (1 9, MHNG); paratype, Pakistan, North-West Frontier Province, ca. $1.5 \mathrm{~km} \mathrm{~N}$ of Islamabad, ca $800 \mathrm{~m}$, forest under stones, $33^{\circ} 44^{\prime} 30^{\prime \prime} \mathrm{N}, 7^{\circ} 03^{\prime} \mathrm{E}, 2003$, S.V. Ovchinnikov leg. $\left(2{ }^{\top}{ }^{\top}\right.$, 3 우,, SMF 40168).

Charinus troglobius Baptista \& Giupponi, 2002: holotype, Brazil: Bahia, Carinhanha, Serra do Ramalho, Gruna do Zé Bastos, 28 Jun. 2001, R.L.C. Baptista and A.P.L. Giupponi leg. (1 Õ, MNRJ 9067); paratypes, Brazil, Bahia, Carinhanha, Serra do Ramalho, Gruna do Zé Bastos, 28 Jun. 2001, R.L.C. Baptista and A.P.L. Giupponi leg. (9 $\widehat{\jmath} \widehat{\jmath}, 2$ $q$ +, MNRJ 9068); Gruna do Zé Bastos, 28 Jun. 2001, R.L.C. Baptista and A.P.L. Giupponi leg. (1 + , MNRJ 9078).

\title{
Results
}

\author{
Arachnida Cuvier, 1812 \\ Amblypygi Thorell, 1883 \\ Family Charinidae Quintero, 1986 \\ Genus Charinus Simon, 1891 \\ Charinus israelensis sp. nov. \\ urn:1sid:zoobank.org:act:D789C530-EBA5-4774-817E-EBCA7DAC76EB
}

Figs $1-6$

\section{Diagnosis}

Median eyes extremely reduced and median tubercle absent; lateral eyes very reduced; 6- 8 frontal setae on the carapace; basitibia of leg IV divided in four pseudo-articles; trichobothrium of the basitibia IV $(b t)$ at the proximal third of the article; distitibia IV with 16 trichobothria; trichobothrium $b c$ closer to $b f$ than to $s b f$; finger-like gonopods. It differs from C. ioanniticus, by the degree of development of the median and lateral eyes, the number of spines on the pedipalp (femur with four dorsal and four ventral in C. israelensis sp. nov. and five dorsal and five ventral in C. ioanniticus), the shape of the carapace (with a rounded frontal border in C. israelensis sp. nov. and projected anteriorly in C. ioanniticus) and the shape of the frontal process (acute in C. israelensis sp. nov. and rhomboid in C. ioanniticus).

\section{Etymology}

The specific epithet, a Latin adjective, refers to the country where the new species was found.

\section{Type material}

\section{Holotype}

ISRAEL: 9 , Mimlach cave, Lower Galilee, 3251'31.84" N, 35²6'34.94" E, Wizen G. leg., 30 Mar. 2014 (HUJINVAMB 111A).

\section{Paratypes}

ISRAEL: $1+$, locality and date as for holotype, Wizen G. leg. (HUJINVAMB 111B); $3 q q+$, Susita cave, Southern Golan Heights, 3246'46.20" N, 35³9'28.53" E, 2 May 2013, Wizen G. leg. (2 in HUJINVAMB 109, 1 in MNRJ 9307); 1 , same locality as holotype, 13 Jul. 2013, Wizen G. leg. (HUJINVAMB 110). 

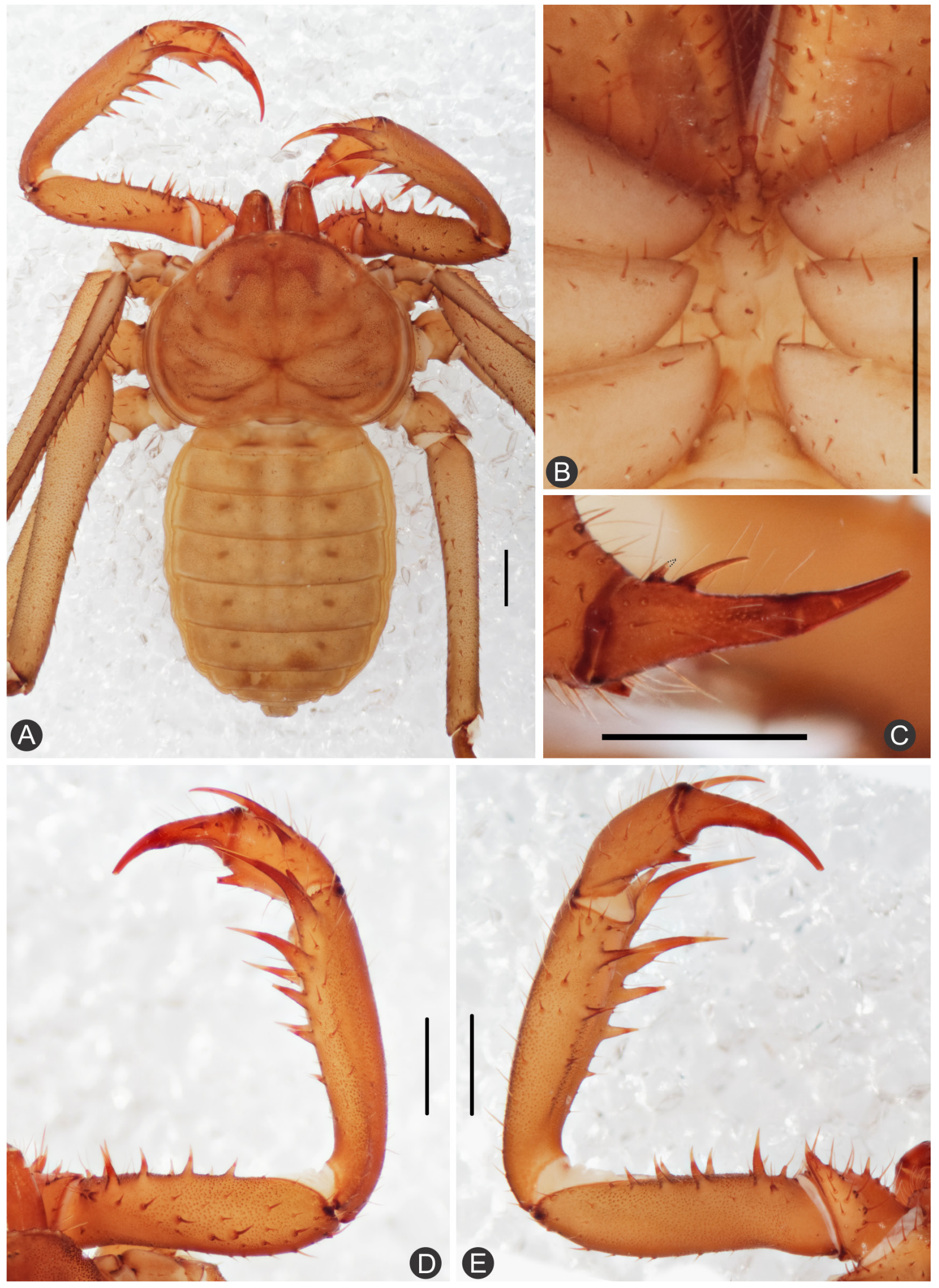

Fig. 1. Charinus israelensis sp. nov. A. Habitus, dorsal view. B. Sternum. C. Frontal view of pedipalp distitarsus. D. Pedipalp, dorsal view. E. Pedipalp, ventral view. Scale bars: $1 \mathrm{~mm}$. 


\section{Description}

Female $(n=4)$

Measurements (in mm). Carapace: length 3.0 (2.76-3.54), width 4.3 (3.92-4.86). Body total length: 8.1 (6.6-10.5). Pedipalp: Femur 2.7 (2.1-3.6), Tibia 3.0 (2.5-4.0), Basitarsus 1.3 (1.2-1.6), Distitarsus 0.9 (0.8-1.0), Tarsal claw 0.7 (0.6-0.9). Leg I: Femur 7.5 (6.9-9), Tibia 12.8 (11.5-15.3), Tarsus 13.4 (13.2-13.8). Leg II: Femur 5.0 (4.5-5.9), Basitibia 3.7 (3.4-4.4), Distitibia 2.5 (2.3-2.7), Basitarsus 1.0 (0.8-1.2), Other tarsal articles 0.7 (0.7-0.7). Leg III: Femur 5.8 (5.3-6.7), Basitibia 4.6 (4.2-5.4), Distitibia 2.7 (2.5-3.0), Basitarsus 1.1 (1.0-1.3), Other tarsal articles 0.8 (0.7-0.9). Leg IV: Femur 4.9 (4.5-4.8), Basitibia I 2.3 (2.1-2.8), Basitibia II 0.6 (0.5-0.8), Basitibia III 0.7 (0.6-0.9), Basitibia IV 1.2 (1.1-1.4), Distitibia 2.5 (2.2-2.8), Basitarsus 1.1 (0.9-1.3), Other tarsal articles 0.7 (0.6-0.9). Size range is shown in Fig. 5A.

CARAPACE (Figs 1A, 4A). Carapace flattened, wider than long (1.4 times), strongly bent downwards below lateral eyes; a thin median furrow reaches the fovea starting from the depression where remnants of median eyes are present. Anterior margin rounded, with six to eight large frontal setae. Many tiny

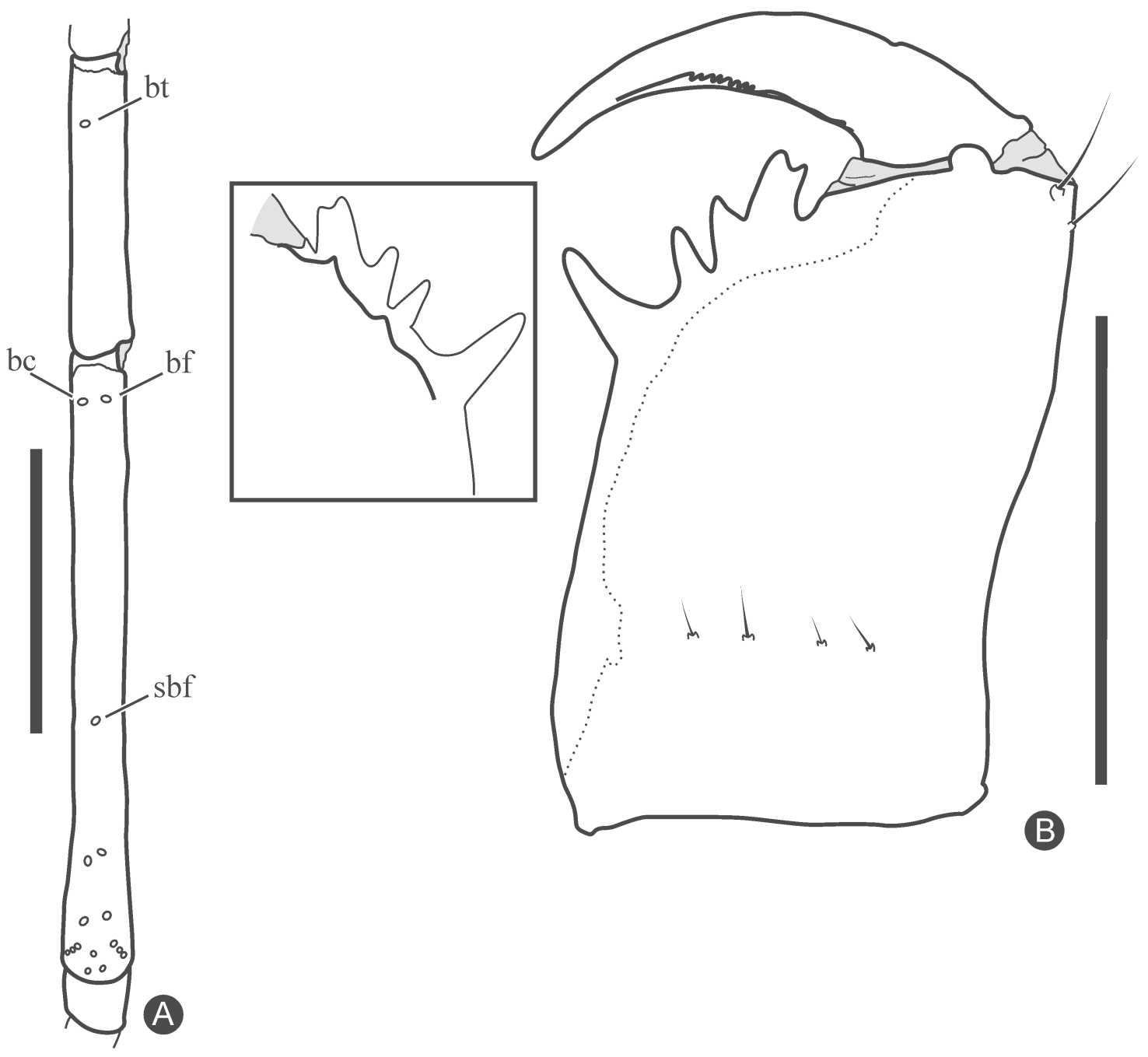

Fig. 2. Charinus israelensis sp. nov. A. Last segment of basitibia and distitibia IV. B. Mesal view of chelicerae, detail of the internal row of teeth in the basal segment. Abbreviations: $b c=$ basocaudal; $b f=$ basofrontal; $\mathrm{bt}=$ basotibial; $\mathrm{sbf}=$ sub-basofrontal. Scale bars: $1 \mathrm{~mm}$. 

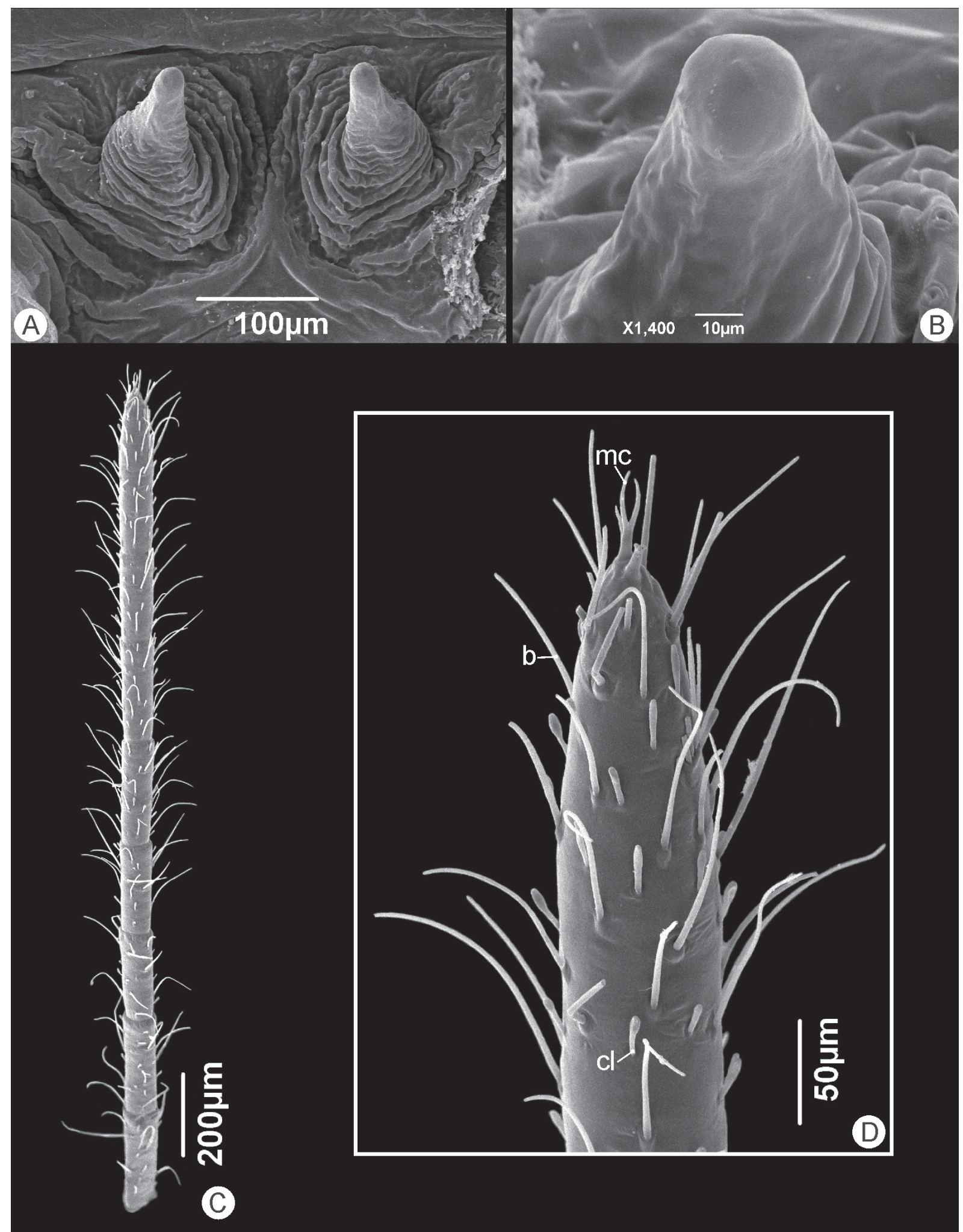

Fig. 3. Charinus israelensis sp. nov., gonopod and leg I. A. Dorsal view of female gonopods. B. Detail of the tip of the finger-like gonopod. C. Dorsal view of the first segments of tarsus I. D. Detail of the tip of the first segment of tarsus I. Abbreviations: $b=$ bristle; $c l=$ club sensillum; $\mathrm{mc}=$ modified claw. 

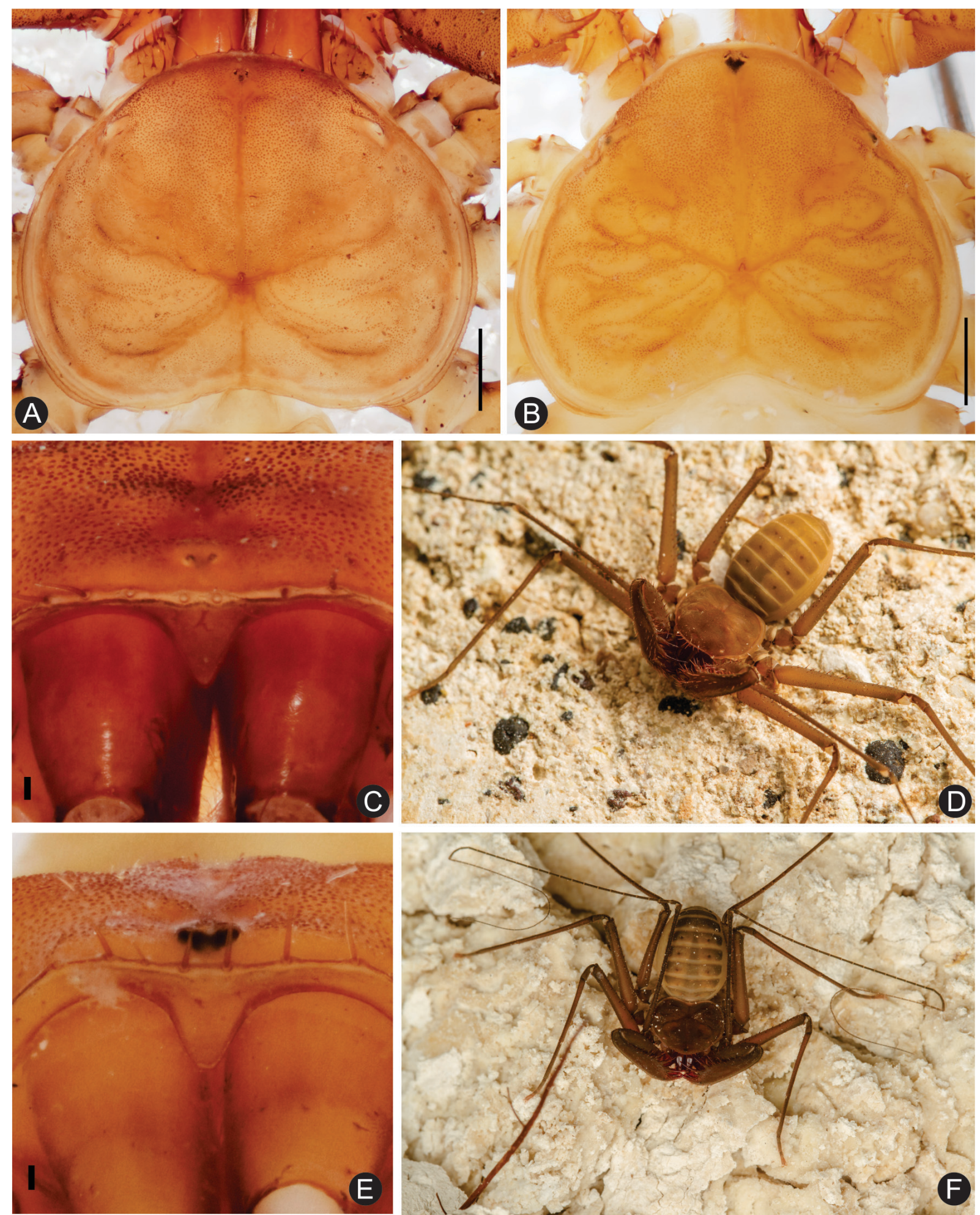

Fig. 4. Carapace, frontal process and habitus. A, C-D. Charinus israelensis sp. nov. B, E-F. C. ioanniticus (Kritscher, 1959). Scale bars: A-B $=1.0 \mathrm{~mm} ; \mathrm{C}-\mathrm{E}=0.1 \mathrm{~mm}$. 
punctuations, more abundant in frontal area; frontal process large, triangular, acute, not visible from above. Three pairs of lateral furrows on carapace, and an oval fovea. 1st pair of furrows placed just behind lateral protrusion; all furrows reach middle line. Eyes small, lateral eyes poorly or non-pigmented, but with tapetum; median eye tubercle absent and eyes almost absent, only a pair of small dots with remnant of lenses.

Sternum (Fig. 1B). Tetra-segmented, all segments well sclerotized. Tritosternum with a round basis and projected anteriorly in a small blunt tubercle, which roughly surpasses the base of the pedipalp coxae, and with two apical, two median and two basal setae, and smaller ones at the base. Middle segment rounded, convex, with two setae and a few small ones. Third segment also rounded and convex, subequal to the middle segment, with two setae and several small ones. Sternites separated from each

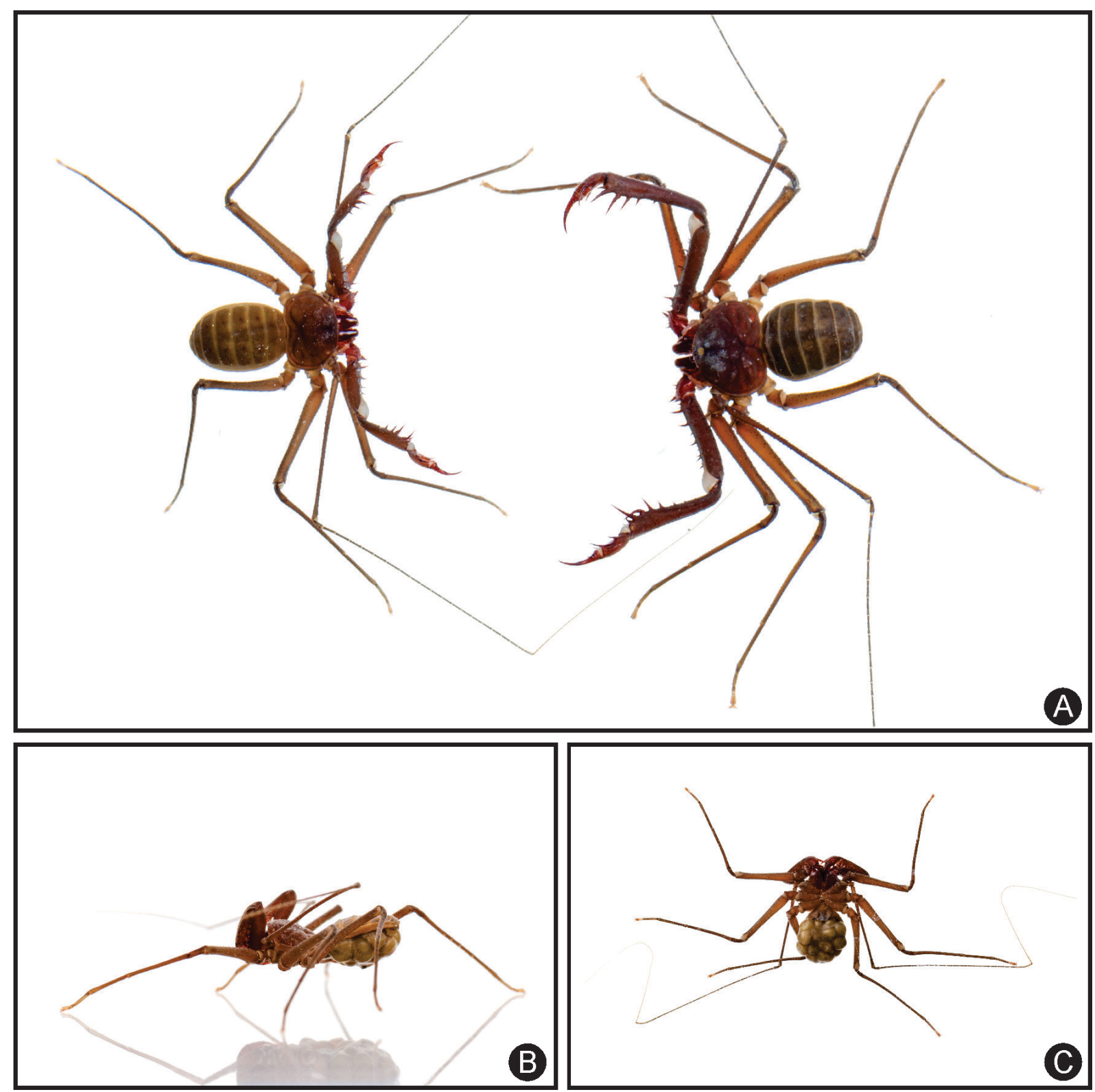

Fig. 5. Live specimens of Charinus israelensis sp. nov. A. Two specimens showing the size range. B. $q$ carrying eggsacs, lateral view. C. $q$ carrying egg sacs, ventral view. 
other by half the diameter of the middle segment. Metasternum simple, with two pairs of small setae in a row on distal region.
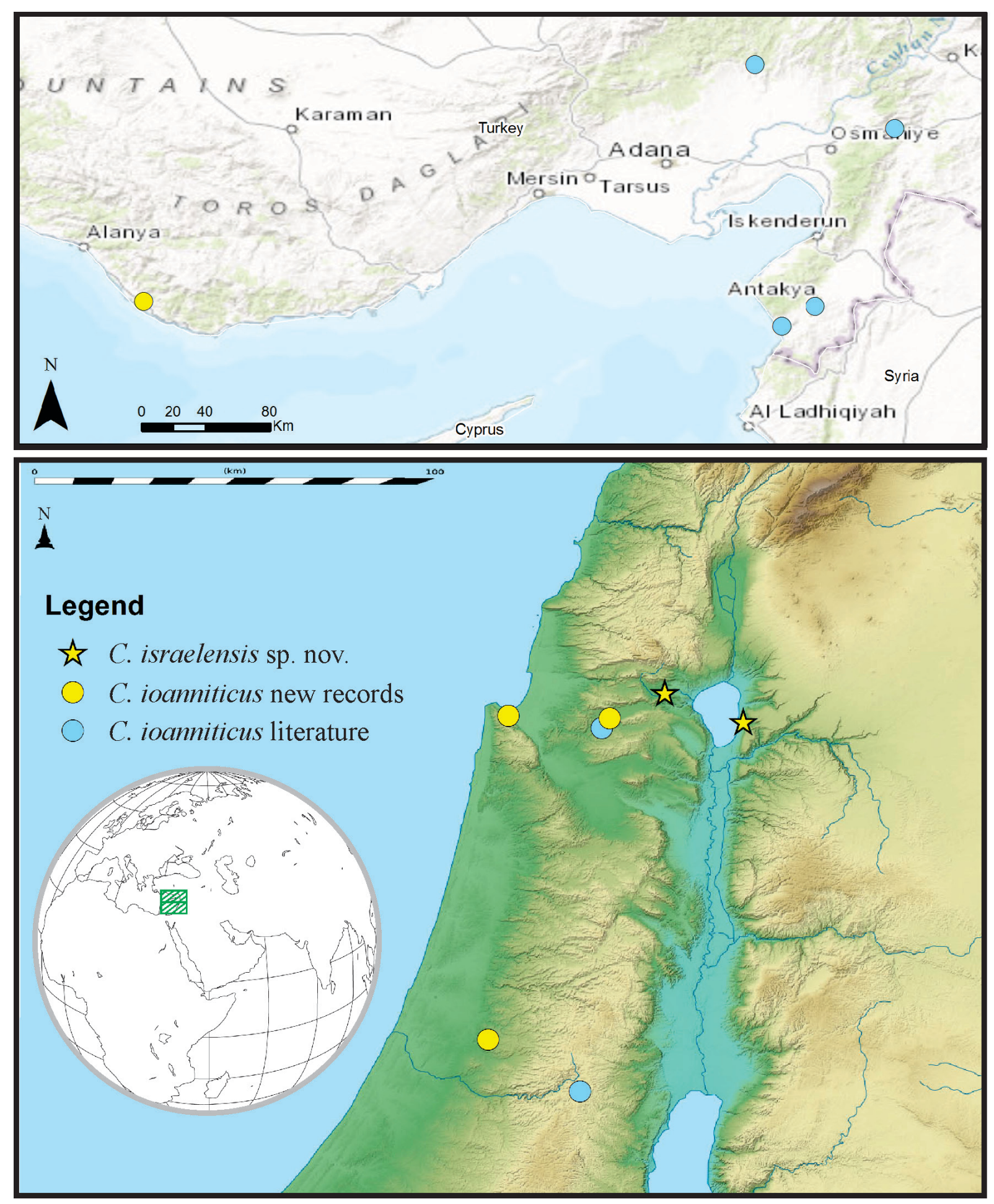

Fig. 6. Distributional map of Charinus Simon, 1892 in Turkey and Israel. 
AвDomen (Figs 1A, 5B-C). Oblong, with almost indistinguishable punctuations, finer than those on the carapace. Ventral sacs developed, without ventral sac covers. When carrying the eggsac, the abdomen is slender and concave; the egg sac is wider than the abdomen, and no fold surrounds it.

Chelicera (Fig. 2B). Cheliceral furrow with four internal teeth; first tooth (upper) bifid, Ia slightly smaller than $\mathrm{Ib}$. Second tooth geminated with the first $(\mathrm{Ia}+\mathrm{Ib})$. Second and third teeth subequal. Fourth tooth one third larger than II and III and subequal to Ib. Teeth length: IV $=\mathrm{Ib}>\mathrm{Ia}>\mathrm{II}=\mathrm{III}$. External row with one small denticle in the upper region and small projection in the lower region. Internal surface of basal article with a vertical row of 3-4 large setae. Claw with eight small denticles.

PediPalp. Trochanter (Fig. 1E): large ventral apophysis, located at posterior border of trochanter, spiniform, bearing 13 large setae, with blunt tip pointed forwards; two subequal spines, one in about the center of the anterior row of tubercles, the other at its distal end. Femur (Fig. 1D-E): four dorsal spines (I $>$ II $>$ III $>$ IV) with two prominent setiferous tubercles before first spine; four ventral spines with two setiferous tubercles before the first spine (I > II > III > IV). Tibia (Fig. 1D-E): five spines (I > II > III > IV $>V$ ); two setiferous tubercles distal to spine I, the proximal one about one third length of spine I and the distal one a bit higher than a regular setiferous tubercle; spine II two thirds of spine I, and spine III one third of spine I. Spines I and II with four setiferous tubercles on its first third. Three ventral spines (I > II > III), the proximal one a bit larger than a setiferous tubercle. Basitarsus (Fig. 1D-E): two dorsal spines, the basal one two thirds the size of the distal one. One ventral spine at distal half, two thirds the size of basal dorsal spine. Distitarsus (Fig. 1C-E): two large curved spines, the distal half the size of the article, and the basal half the size of the distal spine. Cleaning organ about half of the article length. Claw (Fig. 1C): long, with an acute, curved tip.

Legs. All setose. Ventral corner of the prolateral face of femora II-IV projecting in a distinct spiniform process. Femur length: I > III > II > IV. Tibia I with 21 articles. Tarsus (basitarsus + distitarsus) I with 37 articles; modified claw at tip of leg (Fig. 3C-D); leg covered with many bristles (b) and club sensilla (cl). Leg IV: Basitibia: divided into four pseudo-articles, with one trichobothrium (Fig. 2A) on the proximal third of the last pseudo-segments. Distitibia (Fig. 2A): two basal and 14 distal trichobothria (total of 16); trichobothrium $b c$ closer to $b f$ than to $s b f$, which is displaced to close to $s f-s c$. Basitibia-distitibia length: $\mathrm{DT}>\mathrm{BT} 1>\mathrm{BT} 4>\mathrm{BT} 3>\mathrm{BT} 2$.

COLOR PATTERn (in alcohol) (Figs 1, 4A). Chelicerae, pedipalps and carapace yellowish-brown. Legs lighter colored. Abdomen pale yellow. Color of live animals (Figs 4D, F, 5): Chelicerae burgundy, pedipalps and carapace reddish-brown. Some individuals have tiny spots of dark pigment anteriorly to the depression that marks the location of the missing median eyes. Legs yellowish-brown. Abdomen pale yellow. Egg sac tanned and dark brown. All setae red.

GenitaLia. Female gonopod (Fig. 2A-B): posterior margin of genital operculum straight, with few setae along its margin and on its surface. Gonopods finger-like appendage vestiges, forming a wrinkled and folded cushion, with a broad base narrowing to a thin straight apical appendage vestige; deep in the genital atrium. Gonopod very similar to that of its closest related species C. ioanniticus.

\section{Male \\ Unknown.}

\section{Natural history}

Charinus israelensis sp. nov. was found only in warm, humid man-made caves in northern Israel. Females were collected from March to July (the caves were not visited in the autumn and winter season to avoid disturbing a population of Rhinolophus bats that hibernate in the cave). Although we found 
several small-sized arthropods in the caves (e.g., Blattodea, Thysanura), the most frequently encountered prey items were spiders of the genus Loxosceles and isopods. Juveniles of $C$. israelensis sp. nov. feed mainly on Psocoptera dwelling on the cave floor. This species is tolerant to conspecifics compared to other Charinus species, with individuals often found in close proximity $(\mathrm{ca} 20 \mathrm{~cm}$ ) to each other. Gravid females are more isolated and show aggression towards other individuals (Fig. 5A). The egg sac contains 9-30 eggs (Fig. 5B-C). Egg measurements: $1.3-1.4 \mathrm{~mm}$ in diameter. At $25^{\circ} \mathrm{C}$, egg development takes ca 90 days. The hatching praenymphae are white and measure $2-2.2 \mathrm{~mm}$. They climb and stay on the mother's back for 12 days, after which they molt into protonymphae measuring $2.5 \mathrm{~mm}$ in length.

\section{Distribution}

Known from the type locality (Mimlach cave, Lower Galilee) and from Susita, Southern Golan Heights, both in northern Israel (Fig. 6).

\section{Key to the Charinus species group and to the species of the bengalensis species group}

The three Charinus species groups (australianus, bengalensis and brasilianus) can be identified by the different shape of the female genitalia (Weygoldt 2005). Here we provide a key to the species groups of Charinus, including references to images of each type of female gonopod, and a key to all species of the bengalensis species group.

\section{Key to the species groups of Charinus:}

1. Female with thin, finger-like gonopods (Weygoldt 2005: figs 4, 8)

C. bengalensis species group (next key)

- Female with rounded, cushion-like gonopods (Weygoldt 2006: figs 1-10)

C. australianus species group-

- Female with sucker-like gonopods (Vasconcelos et al. 2014: figs 17-18)

C. brasilianus species group

\section{Key to the Charinus species of the bengalensis group:}

1. Basitiba IV divided into two pseudo-articles (Weygoldt et al. 2002: fig 12) .....................2

- Basitiba IV divided into three pseudo-articles (Delle Cave et al. 2009: fig. 3) ..................... 3

- Basitiba IV divided into four pseudo-articles (Weygoldt 2006: fig. 30) ...........................4

2. Reduced lateral and median eyes, standard size legs, pedipalps held horizontally ...................................................... socotranus Weygoldt, Pohl \& Polak, 2002

- No median and lateral eyes, elongate legs, pedipalps turned upwards

.C. stygochthobius Weygoldt \& Van Damme, 2004

3. Female genitalia with curved, rigid finger-like appendage vestiges; genital operculum with pointed apex; eyes well developed

C. bengalensis (Gravely, 1911)

- Female genitalia with straight, soft finger-like appendage vestiges; genital operculum with curved apex; eyes well developed ........................... pakistanus Weygoldt, 2005

- Female genitalia with straight, soft finger-like appendage vestiges; genital operculum with straight apex; median eyes absent, vestiges of the lateral eyes

C. omanensis Delle Cave, Gardner \& Weygoldt, 2009

4. Eyes well developed; female genital operculum with a steep ventral flexure at about two thirds of its length; tibia I with 23 and tarsus I with 41 articles ............. africanus Hansen, 1921

- Median eyes, tubercle and lateral eyes present and prominent (Fig. 4B), frontal border of carapace projected anteriorly (Fig. 4B), frontal process rhomboid (Fig. 4E), femur with five dorsal and ventral spines; tibia I with 21 and tarsus I with 37 articles ......C. ioanniticus (Kritscher, 1959) 
- Median eyes extremely reduced and tubercle absent and lateral eyes extremely reduced (Fig. 4A), frontal border of carapace rounded (Fig. 4A), frontal process acute (Fig. 4C), femur with four dorsal and ventral spines; tibia I with 21 and tarsus I with 37 articles ............... israelensis sp. nov.

\section{New localities of Charinus ioanniticus}

During a biospeleological study in Israel, several specimens of $C$. ioanniticus were collected from manmade caves around the country, all of them new records for the species. The localities are: 1) Haruba cave, central Israel; 2) several caves in Haifa city (along Carmel Mountain Ridge and along the Northern Coastal Plain), northwestern Israel; 3) Khirbet Roma, Beit Netofa, north Israel (Fig. 6B). One of the caves in Haifa (Al-'Atiqa cave) is particularly interesting as it is a man-made burial cave excavated in kurkar sandstone, less than $200 \mathrm{~m}$ from the coastline. The cave is slightly below sea level (one of the chambers is flooded with brackish water). This is, to our knowledge, the first record of a C. ioanniticus populations living below sea level. Additionally, new findings were made in the city of Jerusalem, such as in the entrance of the city (Lifta Tunnel) and in Rehavia (Metudela).

One additional new record is from the Yalan Dünya Cave (Beyrebucak Village, Gazipaşa District, Antalya Province) in Turkey (Fig. 6A), a private, touristic cave which is being gradually destroyed by human activities (Aşan Baydemir et al. 2015). This record extends the known distribution of C. ioanniticus in Turkey, despite being restricted to the southern region, close to the Mediterranean Sea.

\section{Discussion}

Charinus ioanniticus is a parthenogenetic and synanthropic species known from various localities in East Mediterranean countries (Weygoldt 2005). It was described by Kritscher (1959) from Rhodos Island, Greece, and later found in other Greek Islands (Weygoldt 1972), Israel (Kraus 1961; Rosin \& Shulov 1960), Turkey (Kovařík \& Vlasta 1996; Weygoldt 2005; Seyyar \& Demir 2007) and Egypt (ElHennawy 2002).

In Israel, Charinus ioanniticus is uncommon and usually encountered in man-made habitats, such as the walls of old buildings and humid rooms. A similar distribution is also observed in the Caribbean C. acosta (Quintero, 1983), another parthenogenetic species able to live in anthropic areas (Armas 2000; Teruel 2011), and the Amazonian C. vulgaris Miranda \& Giupponi, 2011, which is not found inside buildings, but in secondary forests and scrapyards (Miranda \& Giupponi 2011). Prior to this study, most of the specimens from Israel were collected from a sewerage system in a single neighborhood in the city of Jerusalem (Judaean Mountains, central Israel). A single specimen was also collected from an archeological site (Sepphoris, Fig 6, Kraus 1961).

Like other Charinus species, C. ioanniticus inhabits places protected from direct sunlight and with high humidity. In addition to dark man-made habitats, caves are perfect habitats for Charinus species to occupy, and this environment can exert strong selective pressures, leading over time to speciation events (Barr Jr. \& Holsinger 1985). Species found in caves can have different ecological-evolutionary specializations, being restricted to life in cavities (troglobites), or having strong affinities to caves but being able to live outside them (troglophiles), or living in caves but being required to leave periodically (trogloxenes) for various needs (Sket 2008). Speciation in caves is a relatively fast event (Barr Jr. \& Holsinger 1985) that can happen under a variety of conditions, even when gene flow is present among populations (Nosil 2008). Troglobite species usually have morphological adaptations such as reduction or complete loss of vision and pigmentation, as well as elongation of appendages (Sket 2008; Trajano 2005). The morphological differences that arise in cave animals through time can fit in two main types of changes: those that lead to the reduction of characters and those that improve characters (Klaus et al. 2013). Reductive and constructive traits tend to reduce costly traits (e.g., visual system, pigmentation) 
(Riesch et al. 2011; Tan et al. 2005) and to enlarge certain functional features (e.g., leg and setae length), respectively (Klaus et al. 2013).

Among all troglobite Charinus species known so far, only C. stygochthobius Weygoldt \& van Damme, 2004 and C. troglobius have depigmentation of the body, elongated appendices and pedipalp spines, and an almost complete absence of eyes. In the other species living in caves (e.g., C. eleonorae; C. bordoni Gonzalez-Sponga, 2002 and C. taboa Vasconcelos, Giupponi \& Ferreira, 2016), those characters do not occur simultaneously, showing that this set of features is rare within Amblypygi, even in species considered troglobites or troglophiles. The new species of Charinus was found thus far solely in caves in northern Israel, and has a pronounced reduction of the visual system. Although intensive searches for other populations in the open and experiments with specimens outside the cave environment to assess their survival capability were not done, we suggest that $C$. israelensis sp. nov. is a troglophile species.

Charinus israelensis sp. nov. belongs to the $C$. bengalensis species group, which includes $C$. africanus Hansen, 1921, C. bengalensis, C. ioanniticus, C. omanensis Delle Cave, Gardner and Weygoldt 2009, C. pakistanus, C. socotranus Weygoldt, Pohl and Polak, 2002 and C. stygochthobius. This group is characterized by the finger-like female gonopods with a wrinkled and folded cushion base. Charinus israelensis sp. nov. can be distinguished from $C$. africanus by the weakly developed median eyes, the high number of pedipalp spines, the absence of the strong transverse flexure in the middle of the female genital operculum and of the median elongation in the posterior border of the operculum (Weygoldt 2008), absence of flaps bent posteriorly over a small invagination in the tip of the finger-like process, by the position of the trichobothrium $b c$ on distitibia IV, and by the number of articles in tibia and tarsus I. Charinus israelensis sp. nov. differs from C. omanensis by the number and size of the pedipalp spines, position of the trichobothrium $b c$ on distitibia IV, and development of the median eyes. It differs from C. pakistanus by the absence of concave areas on the posterior margin of the genital operculum, the position of the bifid tooth in relation to tooth II in the basal segment of the chelicerae, the high number of basitibia IV articles (four in the new species and three in C. pakistanus), the high number of articles in tarsus I (37 in C. israelensis sp. nov. and 35 in C. pakistanus) and the development of the median eyes (weakly developed in $C$ israelensis sp. nov. and well developed in C. pakistanus). Lastly, it differs from C. stygochthobius by the absence of a small elongation in the middle of the genital operculum, the position of the trichobothrium $b c$ on distitibia IV, the number and size of spines on the pedipalp and the development of the median eyes.

Based on morphology, Weygoldt (2005) considered Charinus ioanniticus to be more closely related to $C$. bengalensis and C. socotranus than to any other species. Consequently, $C$. israelensis sp. nov. is also morphologically similar to those species. Charinus israelensis sp. nov. differs from C. bengalensis by not having the genital operculum pointed posteriorly, the high number of teeth in the cheliceral claw, the weakly developed median eyes, and the high number of spines on the pedipalp; it differs from $C$. socotranus by the shape of the genital operculum, the position of the trichobothrium $b c$ on distitibia IV, and the number of pedipalp spines.

The new species differs from the closely related Charinus ioanniticus by the shape of the carapace (Fig. 4A-B), the smaller number of pedipalp spines, the smaller size, and the acute shape of the frontal process. The gonopods of $C$. israelensis sp. nov. and $C$. ioanniticus are very similar; as $C$. ioanniticus is a parthenogenetic species (Weygoldt 2005), it could be that the new species has the same reproductive strategy, which leads to reduced selective pressure on the genital region to modify it. Yet, additional nonmutually exclusive explanations could be convergent evolution or recent differentiation. Live specimens are being raised in the laboratory and the parthenogenesis hypothesis will be tested. 
This is the first detailed description of a leg I of a Charinidae species and it is possible to note the reduced number of sensilla when compared to the leg of Phrynidae and Phrynichidae (Delle Cave 1975; Igelmund 1987). The antenniform tarsus in the latter two families is covered with many sensilla (Beck \& Foelix 1974; Beck et al. 1977; Beck \& Görke 1974; Delle Cave 1975), and Igelmund (1987) named the different kinds of sensory structures as bristles, club sensilla, porous sensilla, rod sensilla, leaf-like hairs (also called feather hairs), trichobothria, "pit organ", "plate organ" and slit sense organs. C. israelensis sp. nov. has only bristles, club sensilla and a modified claw. The lack of other sensory structures and organs on leg I is interesting, since $C$. israelensis sp. nov. is possibly a troglobite species and, thus, relies entirely on its sensory structures, but not on its vision, to find food and avoid predators.

\section{Acknowledgements}

We would like to thank Adriano Kury (MNRJ), Hörweg Christoph (NHMW), Lorenzo Prendini (AMNH), Peter Jäger (SMF), Peter J. Schwendinger (MHNG) and Sarah Whitman (MZUF) for loan of material. Nikolaj Scharff provided laboratory facilities and Hanne Espersen (both ZMUC) helped with old and obscure literature. Yael Lubin kindly revised the English. We are also grateful to Kadir Boğac Kunt for the donation of one specimen to ZMUC and for providing bibliography. Boaz Langford from The Cave Research Unit, Shmulik Cohen from the Nature and Parks Authority in Israel, and Eran Levin, Efraim Cohen and Igor Armiach assisted in locating and collecting specimens in the field. Avi Ben Zaken, Boaz Zur, Segev Shalmon, Ori Segev and Nadav Biran contributed valuable information about new localities of $C$. ioanniticus. Personnel at the SEM Platform Rudolf Barth (IOC-FIOCRUZ) - Roger Magno Macedo Silva, Wendell Girard Dias and Rômulo Custódio dos Santos - provided SEM facilities. GSM thanks to the Coordenação de Aperfeiçoamento Pessoal de Nível Superior (CAPES, Brazil) for the Ph.D. Scholarship (Process number 8922-13-6). This study was supported by The Israel Taxonomy Initiative (ITI) Biodiversity surveys grant, and by an ITI fellowship to SA. This is publication no. 902 of the Mitrani Department of Desert Ecology, Ben-Gurion University, Israel.

\section{References}

Armas L.F. 2000. Parthenogenesis in Amblypygi (Arachnida). Avicennia 12/13: 133-134.

Aşan Baydemir N., Genç M., Şimşek Gür M., Atasoy D., Süplün A. \& Kolbasar Ö.F. 2015. İnsan kaynaklı mağara tahribi ve yarasaların korunması üzerine bir ön çalışma. Journal of Anatolian Natural Sciences 6: 191-197.

Baptista R.L.C. \& Giupponi A.P.L. 2002. A new troglomorphic Charinus from Brazil (Arachnida: Amblypygi: Charinidae). Revista Ibérica de Aracnología 6: 105-110.

Barr Jr. T.C. \& Holsinger J.R. 1985. Speciation in cave Faunas. Annual Review of Ecology, Evolution, and Systematics 16: 313-337. http://dx.doi.org/10.1146/annurev.es.16.110185.001525

Beck L. \& Foelix R. 1974. Über die Haarsensillen des Geisselspinne Admetus pumilio (Arach., Amblypygi). Naturwissenschaften 61: 327-328.

Beck L. \& Görke K. 1974. Tagesperiodik, Revierverhalten und Beutefang der Geisselspinne Admetus pumilio C.L. Koch im Freiland. Zeitschrift für Tierpsychologie 35: 173-186.

Beck L., Foelix R., Gödecke E. \& Kaiser R. 1977. Morphologie, Larvalentwicklung und Haarsensillen des Tastbeinpaares der Geisselspinne: Heterophrynus longicornis Butler (Arach., Amblypygi). Zoomorphologie 88: 259-276.

Delle Cave L. 1975. On some sense organs on the first pair of legs of Damon daidema Simon, 1876 (Amblypygi Arachnida). Monitore Zoologico Italiano (n.s.) 9: 203-211. 
Delle Cave L., Gardner A.S. \& Weygoldt P. 2009. A new troglomorphic whip spider of the genus Charinus from the Sultanate of Oman (Amblypygi: Charinidae). Fauna of Arabia 24: 129-134.

El-Hennawy H.K. 2002. The first record of Amblypygi from Egypt. The Journal of Arachnology 30: 452-453. http://dx.doi.org/10.1636/0161-8202(2002)030\%5B0452:TFROAF\%5D2.0.CO;2

Gavish-Regev E., Aharon S., Armiach I. \& Lubin Y. 2016. Cave survey yields a new spider family record for Israel. Arachnologische Mitteilungen 51: 39-42. http://dx.doi.org/10.5431/aramit5105

Giupponi A.P.L. \& Miranda G.S. 2016. Eight new species of Charinus Simon, 1892 (Arachnida: Amblypygi: Charinidae) endemic for the Brazilian Amazon, with notes on their conservational status. PLoS One 11: e0148277. http://dx.doi.org/10.1371/journal.pone.0148277

Husemann M., Schmitt T., Zachos F.E., Ulrich W. \& Habel J.C. 2014. Palaearctic biogeography revisited: evidence for the existence of a North African refugium for Western Palaearctic biota. Journal of Biogeography 41: 81-94. http://dx.doi.org/10.1111/jbi.12180

Igelmund P. 1987. Morphology, sense organs, and regeneration of the forelegs (whips) of the whip spider Heterophrynus elaphus (Arachnida, Amblypygi). Journal of Morphology 193: 75-89. http:// dx.doi.org/10.1002/jmor.1051930108

Klaus S., Mendoza J.C.E., Liew J.H., Plath M., Meier R. \& Yeo D.C.J. 2013. Rapid evolution of troglomorphic characters suggests selection rather than neutral mutation as a driver of eye reduction in cave crabs. Biology Letters 9: 20121098. http://dx.doi.org/10.1098/rsbl.2012.1098

Kovařík F. \& Vlasta D. 1996. First report of Amblypygi (Charinidae: Charinus ioanniticus) from Turkey. Klapalekiana 32: 57-58.

Kraus O. 1961. Charontidae aus Israel, ein zoogeographisch bemerkenswertes Vorkommen (Arach., Pedipalpi - Amblypygi). Senckenbergiana Biologica 42: 491-493.

Kritscher E. 1959. Ergebnisse der von Dr. O. Paget und Dr. E. Kritscher auf Rhodos durchgeführten zoologischen Exkursionen. II. Pedipalpi (Amblypygi). Annalen des Naturhistorischen Museums in Wien 63: 453-457.

Miranda G.S. \& Giupponi A.P.L. 2011. A new synanthropic species of Charinus Simon, 1892 from Brazilian Amazonia and notes on the genus (Arachnida: Amblypygi: Charinidae). Zootaxa 2980: 61-68.

Miranda G.S., Giupponi A.P.L. \& Wizen G. 2016. Two new species of whip spider (Amblypygi): an epigean and a cave dwelling Charinus Simon, 1892 from Belize. Zootaxa 4098: 545-559. http://dx.doi. org/10.11646/zootaxa.4098.3.7

Nosil P. 2008. Speciation with gene flow could be common. Molecular Ecology 17: 2103-2106. http:// dx.doi.org/10.1111/j.1365-294X.2008.03715.x

Quintero D.J. 1981. The amblypygid genus Phrynus in the Americas (Amblypygi, Phrynidae). The Journal of Arachnology 9: 117-166.

Riesch R., Plath M. \& Schlupp I. 2011. Speciation in caves: experimental evidence that permanent darkness promotes reproductive isolation. Biology Letters 7: 909-912. http://dx.doi.org/10.1098/ $\underline{\mathrm{rsbl} .2011 .0237}$

Rosin R. \& Shulov A. 1960. Representatives of the order Amblypygi (Arachnida) found in Israel. Bulletin of the Research Council of Israel 9B: 167-168.

Seyyar O. \& Demir H. 2007. A new locality for Charinus ioanniticus (Kritscher, 1959) (Amblypygi: Charinidae) in Turkey. Serket 10: 109-111. 
Sket B. 2008. Can we agree on an ecological classification of subterranean animals? Journal of Natural History 42: 1549-1563. http://dx.doi.org/10.1080/00222930801995762

Tan S., Amos W. \& Laughlin S.B. 2005. Captivity selects for smaller eyes. Current Biology 15: R540R542. http://dx.doi.org/10.1016/j.cub.2005.07.019

Teruel R. 2011. Nuevos registros de Charinus acosta (Quintero, 1983) en Cuba (Amblypygi: Charinidae). Boletín de la Sociedad Entomológica Aragonesa 49: 345-346.

Trajano E. 2005. Evolution of lineages. In: Culver D. \& White W. (eds) Encyclopedia of Caves: 230234. Elsevier Academic Press, Burlington, MA, U.S.A.

Vasconcelos A., Giupponi A.P.L. \& Ferreira R. 2014. A new species of Charinus from Minas Gerais State, Brazil, with comments on its sexual dimorphism (Arachnida: Amblypygi: Charinidae). The Journal of Arachnology 42: 155-162.

Weygoldt P. 1972. Geisselskorpione und Geisselspinnen (Uropygi und Amblypygi). Zeitschrift des Kölner Zoo 15: 95-107.

Weygoldt P. 2005. Biogeography, systematic position, and reproduction of Charinus ioanniticus (Kritscher, 1959) with the description of a new species from Pakistan (Chelicerata, Amblypygi, Charinidae). Senckenbergiana Biologica 85: 1-14.

Weygoldt P. 2006. New Caledonian whip spiders: Notes on Charinus australianus, Charinus neocaledonicus and other south-western Pacific species of the Charinus australianus species group (Chelicerata, Amblypygi, Charinidae). Verhandlungen des naturwissenschaftlichen Vereins in Hamburg 42: 5-37.

Weygoldt P. 2008. Spermatophores, female genitalia, and courtship behaviour of two whip spider species, Charinus africanus and Damon tibialis (Chelicerata: Amblypygi). Zoologischer Anzeiger 247: 223-232. http://dx.doi.org/10.1016/j.jcz.2007.12.002

Weygoldt P., Hans P. \& Polak S. 2002. Arabian whip spiders: four new species of the genera Charinus and Phrynichus (Chelicerata: Amblypygi) from Oman and Socotra. Fauna of Arabia 19: 289-309.

Manuscript received: 19 February 2016

Manuscript accepted: 28 April 2016

Published on: 28 September 2016

Topic editor: Rudy Jocqué

Desk editor: Kristiaan Hoedemakers

Printed versions of all papers are also deposited in the libraries of the institutes that are members of the EJT consortium: Muséum national d'Histoire naturelle, Paris, France; Botanic Garden Meise, Belgium; Royal Museum for Central Africa, Tervuren, Belgium; Natural History Museum, London, United Kingdom; Royal Belgian Institute of Natural Sciences, Brussels, Belgium; Natural History Museum of Denmark, Copenhagen, Denmark; Naturalis Biodiversity Center, Leiden, the Netherlands. 